\title{
PERIPROCEDURAL MYOCARDIAL NECROSIS PREDICTION BY SYNATX SCORE DURING PERCUTANOUS CORONARY INTERVENTION IN DIABETIC PATIENTS.
}

\author{
Mahmoud Diaa Samir El-Menshawy, Tarek Ahmad Naguib, Ghada Ibrahiem Mohammed Ibrahiem and \\ El-Sayed Nabeeh Ali El-Shafey* \\ Cardiology Department, Faculty of Medicine, Zagazig University.
}

\section{ABSTRACT}

Background: Peri-procedural myocardial injury (PPI) during percutaneous coronary intervention (PCI) is common and associated with a poor outcome. No reliable angiographic or clinical predictors of PPI exist. We evaluated the ability of the SYNTAX score (SXscore), Gensini score and American Heart Association/American College of Cardiology (AHA/ACC) classification to predict PPI.

Methods: 60 patients with chronic stable angina not controlled by medical treatment were included from the day case PCI. Inclusion criteria; patients undergoing insertion of $<30 \mathrm{~mm}$ of stent to a single vessel and/or bifurcation PCI involving a side branch $>2.0 \mathrm{~mm}$ in diameter, and/or patients undergoing double vessel PCI. Exclusion criteria; Patients with heart failure and lesions $>30 \mathrm{~mm}$ in length, patients with high syntax high syntax score, Patients with coronary bypass grafts, previous PCI and patients with instent restenosis. PPI was defined as troponin T elevation $(\mathrm{N} 0.1 \mathrm{ng} / \mathrm{mL})$ at 6-24 h post-PCI.

Results: Patients were classified according to presence or absence of diabetes mellitus (DM) into two groups; group I (non-diabetic patients DM; 33 patients, 23 males, 10 females, their age ranged from 42- 62 years with mean 50.2 \pm 5.3 years), group II (diabetic patients; 27 patients, 16 males, 11 females, their age ranged from 45 -65 years with mean age of $54.4 \pm 5.4$ years).

Patients were reclassified according to syntax score into two groups; group A (with low score (0-22); 48 patients) \& group B (with intermediate score (22-32); 12 patients).

The mean patient SXscore was higher in diabetic patients and non diabetic patients (22.6 vs. 12.4, p=0.0001), Gensini score was significantly higher in diabetic patients $(52.4$ vs. $25.3, \mathrm{p}=0.15)$. Also mean PCI vessel SXscore was higher in vessels associated with PPI (12.1 vs. 7.6, $\mathrm{p}=0.002)$, but not different for PCI vessel Gensini score (16.2 vs. 13.6, $\mathrm{p}=0.42$ ). No vessels with AHA type A lesions were associated with PPI. Higher AHA classification (B and C) were associated with PPI.

In total, 60 patients undergoing PCI to 77 vessels were included in the analysis, There were $43 / 60(71.6 \%)$ patients who had myocardial injury. The incidence of PPI among diabetic patients was higher than non diabetic patients (24/27, $88.9 \%$ vs $19 / 33,57.6 \%$ respectively) reflecting procedural complexity, (long lesion and total occlusion) more in diabetic patients. Indeed, the procedural complexity reflected by the mean patient SXscore was higher in the diabetic patients group than non diabetic patients undergoing day case PCI.

By ROC analysis, we found that a patient with high SXscore of $\geq 15$ can be considered as predictor of PPI with a sensitivity of $95.3 \%$ and specificity of $88.2 \%$.

Conclusion: Higher SXscores are predictive of myocardial injury, whilst AHA type A lesions have a high negative predictive value for PPI.

Keywords: coronary artery disease; PCI; Coronary stenting; PPI, Syntax score, Gensini score; AHA/ACC.

\section{INTRODUCTION}

$\mathbf{P}$ eri-procedural myocardial injury (PPI) during percutaneous coronary intervention (PCI) is common, and may occur in up to $50 \%$ of otherwise successful procedures [1-3].

Even minor elevations in biochemical markers are associated with worse clinical outcomes, including death $[4,5]$. PPI during PCI can be due to plaque shift causing side branch impairment, or plaque embolization causing distal microvascular obstruction [6]. Although the incidence of PPI is associated with worse clinical outcomes, and some insights into the pathophysiology of PPI now exist, there is currently no reliable method of stratifying the risk of PPI in patients undergoing PCI.

The Syntax score (SXscore) has recently been proposed as a comprehensive angiographic scoring algorithm incorporating several validated angiographic classifications based on the morphology and location of coronary artery disease within the coronary tree $[7,8]$. The SXscore reflects the pattern of atheroma and the technical difficulty of PCI. Each coronary lesion producing a $\geq 50 \%$ luminal obstruction in vessels $\geq 1.5 \mathrm{~mm}$ is scored, however no assessment of plaque burden is incorporated. The Gensini score is an angiographic scoring system that reflects plaque burden based on lesion severity in each coronary segment [9]. However, the pattern of disease such as bifurcation lesions, tortuosity and calcification is not represented. The American College of Cardiology/American Heart Association (ACC/AHA) $[10,11]$ is related and represent target lesion complexity and procedural difficulty. 


\section{AIM OF THE WORK}

The objective of this study was to analyze the value of three currently available scores (SXscore, Gensini and ACC/ AHA) in predicting PPI in patients undergoing PCI for stable angina.

\section{METHODS}

\section{Study design and patient population}

The study include 60 patients were chosen consecutively from day case PCI. Inclusion criteria for this study briefly, patients were enrolled if undergoing insertion of $<30 \mathrm{~mm}$ of stent to a single vessel and/or bifurcation PCI involving a side branch $>2.0 \mathrm{~mm}$ in diameter, and/or patients undergoing double vessel PCI, age below 80 years, normal renal function, and no requirement for intra aortic balloon counter pulsation or planned use of glycoprotein IIb/IIIa inhibition. Exclusion criteria for this study, Patients with previous stent insertion, coronary bypass grafts and recent unstable angina, Patients with heart failure and lesions $>30 \mathrm{~mm}$ in length and patients with high syntax high syntax score were excluded from the present analysis.

Thus in total, 60 patients with stable angina undergoing native vessel PCI were included in the present analysis. All patients received aspirin $75 \mathrm{mg}$, intraprocedural heparin IV bolus $70-100 \mathrm{U} / \mathrm{Kg}$ after sheath insertion (ACT> 200sec) and a loading dose of clopidogrel $300 \mathrm{mg}$ orally $\geq 24 \mathrm{~h}$ prior to PCI.

Troponin $\mathrm{T}$ was measured using the Immulite troponin $\mathrm{T}$ solid phase chemiluminescent enzyme immunometric assay (Diagnostic Product Corporation, Los Angeles, California, USA). The upper cutoff concentration for normality suggested by the manufacturer is $\geq 0.1 \mathrm{ng} / \mathrm{mL}$, and PPI was defined as troponin T elevation ( $\geq 0.1 \mathrm{ng} / \mathrm{mL}$ ) 6-24 h post-PCI.

\section{Angiographic analysis}

Each angiogram was analysed independently by two experienced interventional cardiologists who were blinded to the procedural and troponin T results. Each coronary lesion producing a $\geq 50 \%$ luminal obstruction in vessels $\geq 1.5 \mathrm{~mm}$ was separately scored and added for each coronary vessel to provide the vessel SXscore, and then summed to provide the overall patient SXscore as previously described $[7,8]$ using a dedicated software Percent luminal stenosis was also quantified for each coronary segment, and the Gensini score was calculated for each coronary vessel and summed to provide the overall patient Gensini score as previously described [9]. The modified ACC/ AHA lesion classification was also measured for each treated lesion (A, B or C).

Right dominance: the posterior descending coronary artery is a branch of the right coronary artery (segment 4);
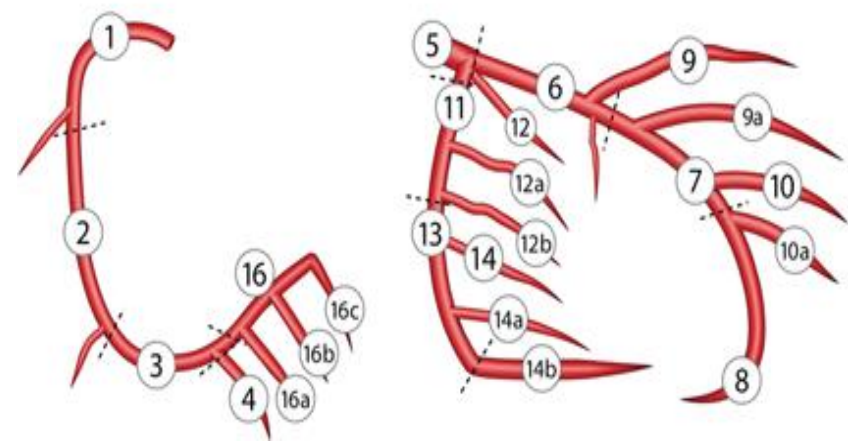

Figure (1): segments definition with right dominance coronary artery. 
Left dominance: the posterior descending artery is a branch of the left coronary artery (segment 15). Codominance does not exist as an option in the SYNTAX score
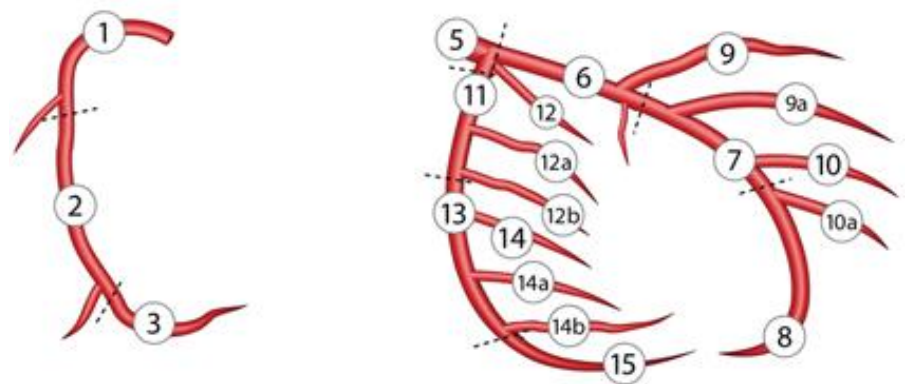

Figure (2): segments definition with left dominance coronary artery.

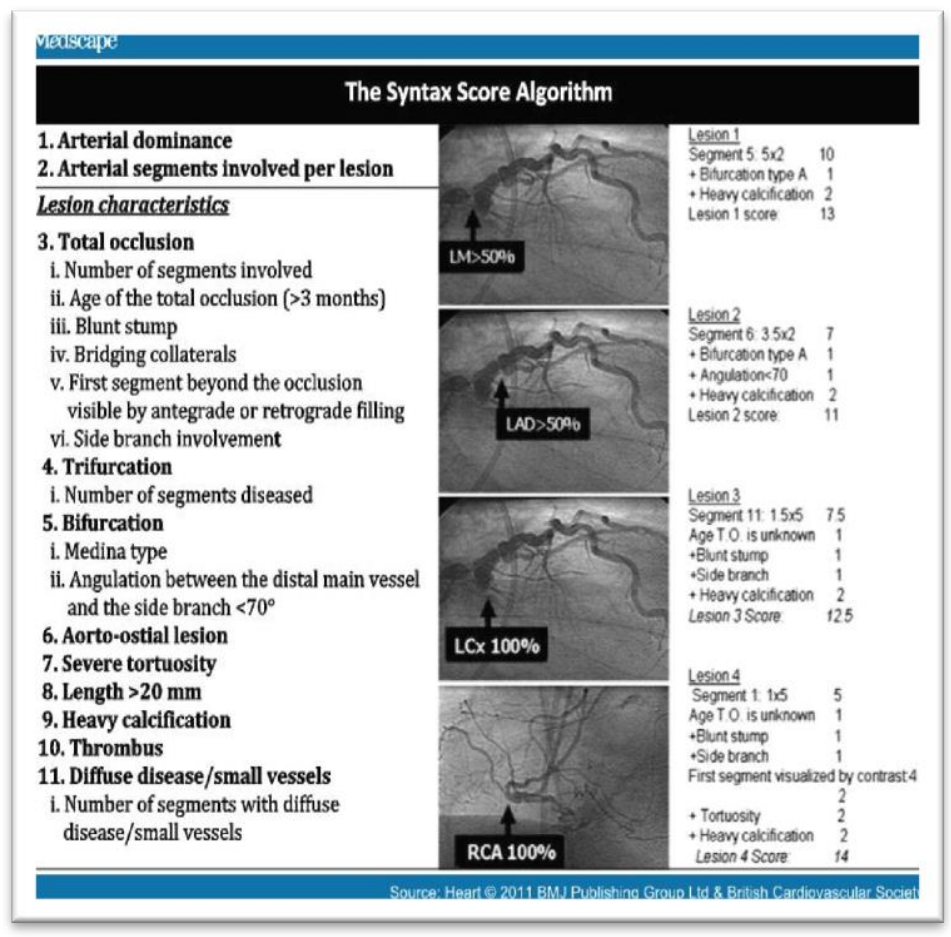

Figure (3). SYNTAX Score (SXscore) algorithm. The algorithm is applied to each individual coronary lesion that has a diameter stenosis $>50 \%$ and located in a vessel $>1.5 \mathrm{~mm}$ in diameter. The individual lesion scores are added together to give the final SXscore.LAD, left anterior descending artery; LCx, left circumflex artery; LM, left main stem; RCA, right coronary artery (7).

\section{STATISTICAL ANALYSIS}

Continuous data are expressed as mean \pm standard deviation. Categorical data are expressed as frequency (percent). Differences between groups (non diabetic patients vs. Diabetic patients) for vessel based and overall SXscore and Gensini score were analysed using the unpaired $\mathrm{T}$ test. A p-value $\leq 0.05$ was considered significant. Optimal cutoff for SXscore in predicting PPI was quantified by receiver operator characteristic (ROC) curve analysis.

\section{RESULTS}

Patients were classified according to presence or absence of diabetes mellitus (DM) into two groups; 
group I (non-diabetic patients DM; 33 patients, 23 males, 10 females, their age ranged from $42-62$ years with mean $50.2 \pm 5.3$ years), group II (diabetic patients; 27 patients, 16 males, 11 females, their age ranged from $45-65$ years with mean age of
$54.4 \pm 5.4$ years).

Patients were reclassified according to syntax score into two groups; group A (with low score (0-22); 48 patients) \& group B (with intermediate score (22-32); 12 patients).

Table (1): Angiographic lesions character and angiographic scores:

\begin{tabular}{|c|c|c|c|c|c|}
\hline Variable & \multicolumn{2}{|c|}{$\begin{array}{c}\text { Group I } \\
\text { Non diabetic } \\
\operatorname{Pt}(n=33)\end{array}$} & \multicolumn{2}{|c|}{$\begin{array}{c}\text { Group II } \\
\text { Diabetic patients } \\
(\mathrm{n}=27)\end{array}$} & $\mathrm{P}$ value \\
\hline \multicolumn{6}{|l|}{ Dominance } \\
\hline Rt no $(\%)$ & 28 & 84.4 & 23 & 85.2 & 0.74 \\
\hline $\mathrm{Lt}$ & 5 & 15.2 & 4 & 14.8 & \\
\hline \multicolumn{6}{|l|}{ Severity of lesion } \\
\hline $50-99 \%$ & 31 & 93.9 & 18 & 66.7 & 0.059 \\
\hline Total occlusion & 2 & 6.1 & $9 *$ & 33.3 & $0.017 *$ \\
\hline Bifurcation lesion & 14 & 42.4 & 18 & 66.6 & 0.09 \\
\hline Trifurcation lesion. & 1 & 3 & 3 & 11 & 0.46 \\
\hline Length $\geq 20 \mathrm{~mm}$ & 16 & 48.5 & $20 *$ & 74.1 & $0.04 *$ \\
\hline Calcification & 5 & 15.2 & 8 & 29.6 & 0.17 \\
\hline Thrombus & 0 & 0 & 2 & 7.4 & 0.56 \\
\hline Small vessel & 9 & 27.3 & 6 & 22.2 & 0.65 \\
\hline Syntax score & \multicolumn{2}{|c|}{$12.4 \pm 4.8$} & \multicolumn{2}{|c|}{$22.6 \pm 5.0 * *$} & $0.001 * *$ \\
\hline Gensini score & \multicolumn{2}{|c|}{$25.3 \pm 14.7$} & \multicolumn{2}{|c|}{$52.4 \pm 24.7 * *$} & $0.001 * *$ \\
\hline \multicolumn{6}{|l|}{ AHA no $(\%)$} \\
\hline Type A & $16^{*}$ & 48.5 & 1 & 3.7 & \\
\hline Type B & 15 & 45.5 & 13 & 48.1 & $0.001 * *$ \\
\hline Type C & 2 & 6.1 & $13 *$ & 48.1 & \\
\hline
\end{tabular}

In total, 60 Patients, patient's angiographic lesions character and angiographic scores are detailed in Table 1. There were increased of angiographic scores in diabetic patients as syntax score, Gensini score and AHA angiographic classification, these results may help to explain the poor prognosis of coronary artery disease among diabetic patients. 
Table (2): PCI data of examined group.

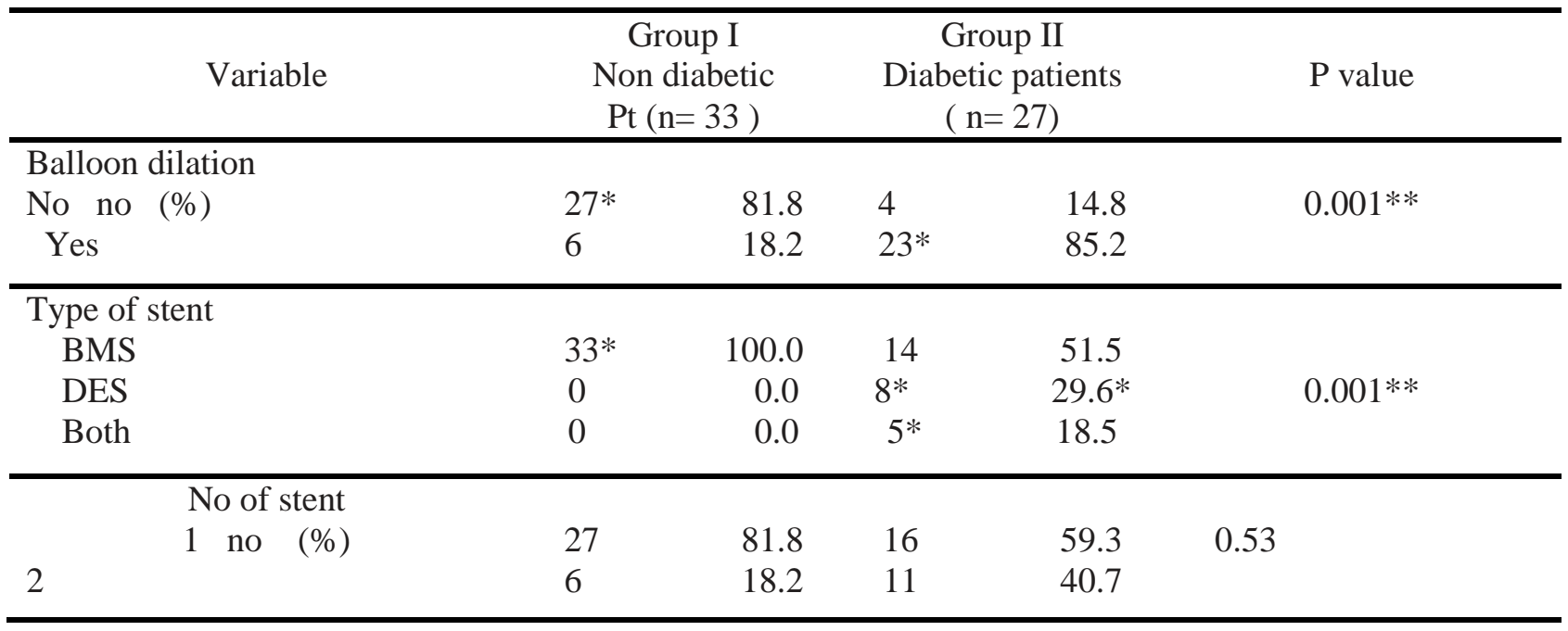

In total, 60 Patients, patient's angiographic lesions character and angiographic scores are detailed in Table 2. There were significant increases of usage of balloon dilation (PTCA) before PCI, double vessel PCI and drug eluting stent in diabetic patient than in non diabetic patients.

\section{Peri-procedural myocardial injury}

Table (3): Myocardial injury (troponin T level $>0.1 \mathrm{ng} / \mathrm{ml}$ ) of study groups.

\begin{tabular}{llllll}
\hline Variable & $\begin{array}{l}\text { Group I } \\
\text { Non diabetic } \\
\text { Pts }(\mathrm{n}=33)\end{array}$ & \multicolumn{2}{l}{$\begin{array}{l}\text { Group II } \\
\text { Diabetic patients }(\mathrm{n}=\text { P value } \\
27)\end{array}$} \\
\hline Myocardial injury & $14 *$ & 42.4 & 3 & 11.1 & $0.007 *$ \\
No $(\mathrm{Tn}<0.1 \mathrm{ng} / \mathrm{ml})$ & 19 & 57.6 & $24 *$ & 88.9 & \\
Yes $(\mathrm{Tn}>0.1 \mathrm{ng} / \mathrm{ml})$ & & & & & \\
\hline
\end{tabular}

In total, 60 patients undergoing PCI to 77 vessels were included in the analysis. Patients with myocardial injury, There were 43/60 (71.6\%) patients who had PPI. The incidence of PPI among diabetic patients was much higher than non diabetic patients $(24 / 27,88.9 \%$ vs $19 / 33,57.6 \%$ respectively).

\section{The Syntax score}

Table (4): Syntax score in diabetic \& non diabetic patients.

\begin{tabular}{lllllll}
\hline & Variable & \multicolumn{1}{c}{$\begin{array}{c}\text { Group I } \\
\text { Non diabetic } \\
\text { patients }(\mathrm{n}=33)\end{array}$} & $\begin{array}{c}\text { Group II } \\
\text { Diabetic patients } \\
(\mathrm{n}=27)\end{array}$ & P value \\
\hline $\begin{array}{l}\text { Syntax score } \\
\text { Low syntax no }(\%)\end{array}$ & 31 & 93.9 & 7 & 63.0 & \\
Intermediate syntax & 2 & 6.1 & 10 & 37.0 & $0.002^{*}$ \\
\hline
\end{tabular}


Table (5): Syntax score and myocardial injury in non diabetic patients.

\begin{tabular}{llllll}
\hline & Variable & $\begin{array}{c}\text { No myocardial injury } \\
(\mathrm{Tn}<0.1 \mathrm{ng} / \mathrm{ml})\end{array}$ & $\begin{array}{c}\text { Myocardial injury } \\
(\mathrm{Tn}>0.1 \mathrm{ng} / \mathrm{ml})\end{array}$ & P value \\
\hline Syntax Score & 14 & 45.2 & 17 & 54.8 & 0.49 \\
Low no $\%$ & 0 & 0.0 & 2 & 100 & \\
Intermediate & & 0.00 & \\
\hline
\end{tabular}

Table (6): Syntax score and myocardial injury in diabetic patients.

\begin{tabular}{|c|c|c|c|c|c|}
\hline Variable & & $\begin{array}{c}\text { No myocardial injury } \\
(\operatorname{Tn}<0.1 \mathrm{ng} / \mathrm{dl})\end{array}$ & & $\begin{array}{l}\text { cardial injury } \\
>0.1 \mathrm{ng} / \mathrm{dl})\end{array}$ & $P$ value \\
\hline \multicolumn{6}{|l|}{ Syntax Score } \\
\hline Low no $\%$ & 3 & 17.6 & 14 & 82.4 & 0.002 \\
\hline Intermediate & 0 & 0.0 & 10 & 100 & \\
\hline
\end{tabular}

Table (7): Coronary arteries lesions in diabetic \& non diabetic patients.

\begin{tabular}{|c|c|c|c|c|c|c|}
\hline \multicolumn{2}{|r|}{ Variable } & \multicolumn{2}{|c|}{$\begin{array}{c}\text { Group I } \\
\text { Non diabetic } \\
(\mathrm{n}=33 \text { patients })\end{array}$} & \multicolumn{2}{|c|}{$\begin{array}{c}\text { Group II } \\
\text { Diabetic } \\
(\mathrm{n}=27 \text { patients })\end{array}$} & \multirow[t]{2}{*}{$P$ value } \\
\hline$\overline{L A D}$ & no $\%$ & & & & & \\
\hline Proximal & & 9 & 27.3 & 11 & 40.7 & $0.004 *$ \\
\hline Mid & & 11 & 33.3 & 15 & 55.6 & \\
\hline No lesion & & 13 & $39.4 *$ & 1 & 3.7 & \\
\hline $\mathrm{LCX}$ & no $\%$ & & & & & \\
\hline Proximal & & 3 & 9.1 & 1 & 3.7 & 0.39 \\
\hline Mid & & 0 & 0 & 1 & 3.7 & \\
\hline Distal & & 3 & 9.1 & 5 & 18.5 & \\
\hline No lesion & & 27 & 81.8 & 20 & 74.1 & \\
\hline $\mathrm{RCA}$ & no $\%$ & & & & & \\
\hline Proximal & & 9 & $27.3 *$ & 1 & 3.7 & $0.04 *$ \\
\hline Mid & & 0 & 0 & 1 & 3.7 & \\
\hline Distal & & 0 & 0 & 1 & 3.7 & \\
\hline No lesion & & 24 & 72.7 & 24 & 88.9 & \\
\hline $\mathrm{D} 1$ & no $\%$ & & & & & \\
\hline Proximal & & 5 & 15.2 & 5 & 18.5 & 0.72 \\
\hline No lesion & & 28 & 84.8 & 22 & 81.5 & \\
\hline OM1 & no $\%$ & & & & & \\
\hline Proximal & & 2 & 6.1 & 1 & 3.7 & 0.67 \\
\hline No lesion & & 31 & 93.9 & 26 & 96.3 & \\
\hline
\end{tabular}

LAD: left anterior descending artery.

RCA: right coronary artery.

D1: first diagonal artery.
LCX: left circumflex artery.

OM1: first obtuse marginal branch. 
Table (8): Relationship between coronary arteries lesions and myocardial injury in examined patients.

\begin{tabular}{|c|c|c|c|c|c|}
\hline Variable & \multicolumn{2}{|c|}{$\begin{array}{l}\text { Without myocardial injury } \\
(\mathrm{Tn}<0.1 \mathrm{ng} / \mathrm{ml}) \\
(\mathrm{n}=17 \text { patients })\end{array}$} & \multicolumn{2}{|c|}{$\begin{array}{l}\text { With myocardial injury. } \\
\quad(\mathrm{Tn}>0.1 \mathrm{ng} / \mathrm{ml}) \\
(\mathrm{n}=43 \text { patients })\end{array}$} & \multirow[t]{2}{*}{$P$ value } \\
\hline no $\%$ & & & & & \\
\hline Proximal & 2 & 11.8 & $18 *$ & 41.8 & $0.012^{*}$ \\
\hline Mid & 4 & 23.5 & 22 & 51.2 & \\
\hline Distal & 0 & 0 & 0 & 0 & \\
\hline No lesion & 11 & 64.7 & 3 & 7 & \\
\hline $\begin{array}{lll}\text { LCX } & \text { no } \%\end{array}$ & & & & & \\
\hline Proximal & 3 & 17.6 & 1 & 2.3 & \\
\hline Mid & 0 & 0 & 1 & 2.3 & $0.02 *$ \\
\hline Distal & 0 & 0 & 8 & $18.6^{*}$ & \\
\hline No lesion & 14 & 82.4 & 33 & 76.8 & \\
\hline $\begin{array}{lll}\text { RCA } & \text { no } & \%\end{array}$ & & & & & \\
\hline Proximal & 3 & 17.6 & 7 & 16.3 & \\
\hline Mid & 0 & 0 & 1 & 2.3 & 0.8 \\
\hline Distal & 0 & 0 & 1 & 2.3 & \\
\hline No lesion & 14 & 82.4 & 34 & 79.1 & \\
\hline D1 $\quad$ no $\%$ & & & & & \\
\hline Proximal & 0 & 0 & 10 & 23.3 & 0.16 \\
\hline No lesion & 17 & 100 & 33 & 76.7 & \\
\hline OM 1 & & & & & \\
\hline Proximal & 2 & 11.8 & 1 & 2.3 & 0.22 \\
\hline No lesion & 15 & 88.2 & 42 & 97.7 & \\
\hline
\end{tabular}

LAD: left anterior descending artery.

RCA: right coronary artery.

D1: first diagonal artery.

\section{The Syntax score}

The mean patient SXscore was higher in patients with PPI compared to those without PPI (22.6 \pm 9.0 vs. $12.4 \pm 8.0, \mathrm{p}=0.0001)$, mean vessel SXscore was also calculated for each treated vessel. The mean vessel SXscore was higher in vessels associated with PPI than those without PPI (12.1 \pm 7.3 vs. $7.6 \pm 5.6, p=0.002)$. Logistic regression
LCX: left circumflex artery.

OM1: first obtuse marginal branch. analysis demonstrated a significant relationship between the SXscore and PPI, such that each unit increase in the SXscore was associated with an increased risk of PPI (sensitivity $95.3 \%$, specificity $88.2 \%$, positive predictive value $95.3 \%$ and negative predictive value $88.2 \%$ ). 


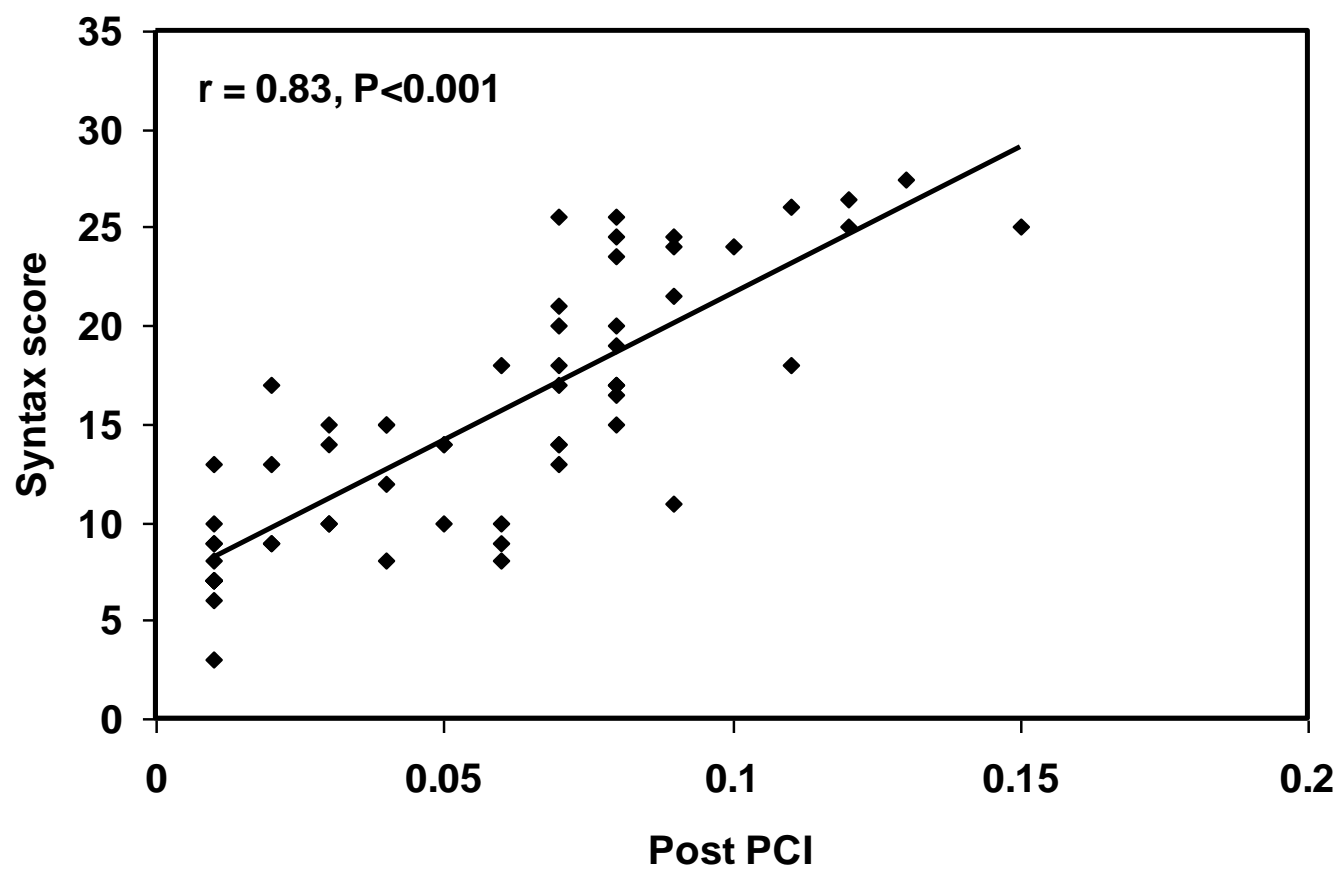

Figure (4): correlation between Syntax score, Low Syntax score, intermediate syntax score and post PCI Troponine T level.

\section{The Gensini score}

The mean patient Gensini score was not statistically different between patients with PPI and no-PPI $(34.2 \pm 18.1$ vs. $27.3 \pm 19.3, \mathrm{p}=$ 0.15). Logistic regression analysis confirmed no significant relationship between the Gensini score and PPI (sensitivity $76.7 \%$, specificity $58.8 \%$, positive predictive value $82.5 \%$ and negative predictive value $50 \%$ ).

\section{The AHA/ACC classification}

No vessels with AHA type A $(n=17)$ or B lesions $(n=28)$ sustained PPI. Higher AHA scores C lesion $(n=15)$ were associated with PPI. Logistic regression analysis confirmed significant relationship between the type B AHA lesion and PPI (sensitivity 65.1\%, specificity $41.2 \%$, positive predictive value $73.3 \%$ and negative predictive value $31.8 \%$ ).

\section{ROC analysis}

By ROC analysis, the SXscore was predictive of PPI (area under curve $=0.83$ ). Choosing a sensitivity: specificity ratio of, a patient SXscore $\mathrm{f} \geq 15$ redicted PPI with a sensitivity of $95.3 \%$ and specificity of $88.2 \%$. At this cutoff, the patient SXscore provided a positive and negative predictive value of $95.3 \%$ and 88.2 $\%$ respectively for PPI. The positive predictive value increased with higher scores. By ROC analysis, the Gensini score produced multiple ties at lower scores, and did not perform better than chance, with an area under the curve of 0.14.

\section{DISCUSSION}

The occurrence of PPI following PCI is common, and such injury is of prognostic importance, with several studies showing an increased risk of death even with minor enzyme elevations following PCI $[4,5]$. Therefore, being able to stratify the risk of PPI in patients undergoing PCI is important, and may help rationalize the use of adjunctive therapies such as glycoprotein IIb/IIIa inhibitors and/or distal embolic protection devices. Practically, tools able to help predict PPI will facilitate the selection of patients for research into the mechanisms of PPI, as well as future therapies designed to minimize PPI and/or improve peri procedural outcomes. Our study demonstrates the positive predictive value of the SXscore for peri procedural injury, with increasing predictive value as the SXscore rises, and the strong negative predictive value of type A/B AHA lesions for PPI.

There were increase incidence of right dominance coronary artery, severity of lesion, bifurcation lesion, trifurcation lesion, calcification, thrombus and small vessel disease in diabetic patients but without statistical significant difference between both groups (diabetic patients and non diabetic 
patients), there were significant high incidence of long lesion and total occlusion more in diabetic patients than non diabetic patients, there were significant increase of Syntax score, Gensini score and type $\mathrm{C}$ lesion of American heart association angiographic classification in diabetic patients than non diabetic patients, there was significant increase of usage of balloon dilation (PTCA) before PCI, double stent, drug eluting stent, peri procedure myocardial injury more in diabetic patient than in non diabetic patients, there were significant higher incidences of myocardial injury in diabetic patients than non diabetic patients but there were significant higher incidences myocardial injury in diabetic patient with intermediate syntax score (23-33) than in non diabetic patient intermediate syntax score (23-33)., LAD and RCA lesion were more frequently present in diabetic patients than non diabetic patients. There were no significant difference regard LCX, D1 and OM1 lesion in diabetic patients and non diabetic patients, the occurrence of myocardial injury was more frequently present with proximal LAD lesion and distal LCX lesion than in RCA, OM1 and D1 lesion.Although the SXscore was originally developed to evaluate patients with triple vessel and/or left main coronary artery, we have demonstrated its predictive power in patients undergoing single or double vessel PCI. In our study, the positive predictive value of a SXscore $\geq 15$ for PPI was $95.5 \%$ compared with a positive predictive value of $73.3 \%$ for an AHA/ACC type B lesion.

Furthermore, the positive predictive value of the SXscore improved with increasing scores, although numbers were small. In comparison, the modified AHA classification scheme does not allow for further stratification and it would appear that the SXscore is superior in predicting PPI for patients undergoing PCI.

The Gensini score was designed to provide an accurate stratification of patients according to the functional status of their coronary disease [9]. We decided to evaluate the Gensini score because unlike the SXscore, the Gensini score is based predominately on plaque burden, stratifying lesions into b $25 \%$, $\leq$ $50 \%, \leq 75 \%, \leq 90 \%, 99 \%$ and $100 \%$ maximal lumen diameter stenosis. In the SXscore however, each lesion is scored only if the percent diameter stenosis is $\geq 50 \%$, and is not further stratified above this level of luminal stenosis, other than for total occlusions. Despite this, the Gensini score was not predictive of
PPI, although a trend was apparent, and the lack of statistical significance could relate to our modest sample size. The ability of the SXscore to assess multiple lesion characteristics including the presence of bifurcation disease, and the type of bifurcation, probably underlies its ability to predict PPI. The SXscore does include a bifurcation classification which is pivotal in predicting side branch loss, and its assessment of lesion length (those $>20 \mathrm{~mm}$ ) does provide for some assessment of plaque burden. These features are lacking in the Gensini score. Currently the SXscore remains under evaluation and the investigators have stated that "some modification may be required as the usefulness of its individual features is determined or as new contributors are identified" [17], such as respect to percent luminal stenosis in the SXscore may be useful in predicting procedural outcomes for patients treated with PCI.

The AHA/ACC classification performed well in identifying patients at very low risk of PPI. No patient with a type A lesion developed PPI, which most likely reflects the absence of characteristics which lead to side branch occlusion or distal embolization and subsequent PPI (i.e. a bifurcation or large plaque burden). Likewise, type B lesions produce minimal myocardial injury, and although these may include bifurcations, by definition, no other high risk features are present, and the side branch is accessible for protection. Type $\mathrm{C}$ lesions were particularly prone to PPI, reflecting extensive plaque burden (lesion length greater than $20 \mathrm{~mm}$ ) and other factors, such as inability to protect a major side branch. The inclusion of CTO in this group may have reduced the predictive value of the score, as no patient with a CTO sustained new myocardial injury, although the total number of such patients treated in our study was small.

\section{Limitation of Study:}

Our study is limited by its moderate sample size and selection bias with the inclusion of patients with stable angina only. We cannot exclude the possibility of a type II error with respect to the predictive power of the Gensini score or SCAI classification for these reasons respectively. Despite these limitations however, we were able to demonstrate the strong positive and negative predictive value of the SXscore and AHA classification for PPI in patients undergoing PCI for stable angina. Procedural techniques including the use of direct stenting, aggressive postdilatation, rotational atherectomy and choice of bifurcation strategy are also likely to modify the risk of peri-procedural necrosis for any given angiographic score or classification. It would seem 
prudent to incorporate these variables when considering the risk of PPI and the use of adjunctive therapies in patients undergoing PCI. Nevertheless, the simple and reliable SXscore and AHA classification are useful risk stratification tools for assessing a patient's baseline risk of PPI prior to coronary intervention.

\section{CONCLUSION}

Our study demonstrates the utility of the SXscore and ACC/AHA classification in stratifying patients into high and low risk of PPI respectively. The SXscore may prove a useful tool in the rationalization of existing therapies aimed at minimizing PPI and/or improving clinical outcomes for patients undergoing PCI, and in the evaluation of new strategies aimed at reducing PPI. The AHA/ACC classification reliably identifies patients at low risk of PPI. Patients undergoing PCI for type A/B1 lesions are at particularly low risk, and thus the AHA/ACC classification is a simple method to screen patients who are suitable for PCI without onsite surgical backup and for selecting patients suitable for PCI with same day hospital discharge.

\section{REFERENCES}

1. Selvanayagam JB, Porto I, Channon K, et al. Troponin elevation after percutaneous coronary intervention directly represents the extent of irreversible myocardial injury: insights from cardiovascular magnetic resonance imaging. Circulation 2005; 111(8):1027-32.

2. Abdelmeguid AE, Topol EJ, Whitlow PL, Sapp SK, Ellis SG. Significance of mild transient release of creatine kinase-MB fraction after percutaneous coronary interventions. Circulation 1996; 94(7):1528-36.

3. Simoons ML, van den Brand M, Lincoff M, et al. Minimal myocardial damage during coronary intervention is associated with impaired outcome. Eur Heart J 1999; 20(15):1112-9.

4. Ellis SG, Chew D, Chan A, Whitlow PL, Schneider JP, Topol EJ. Death following creatine kinase MB elevation after coronary intervention: identification of an early risk period: importance of creatine kinase-MB level, completeness of revascularization, ventricular function, and probable benefit of statin therapy. Circulation 2002; 106(10):1205-10.

5. Akkerhuis KM, Alexander JH, Tardiff BE, et al. Minor myocardial damage and prognosis: are spontaneous and percutaneous coronary intervention-related events different? Circulation 2002; 105(5):554-6.

6. Porto I, Selvanayagam JB, Van Gaal WJ, et al. Plaque volume and occurrence and location of periprocedural myocardial necrosis after percutaneous coronary intervention: insights from delayed-enhancement magnetic resonance imaging, thrombolysis in myocardial infarction myocardial perfusion grade analysis, and intravascular ultrasound. Circulation 2006; 114(7):662-9.

7. Sianos G, Morel MA, Kappetein AP, et al. The Syntax score: an angiographic tool grading the complexity of coronary artery disease. Eurointervention 2005; 1:219-27.

8. Valgimigli M, Serruys PW, Tsuchida K, et al. Cyphering the complexity of coronary artery disease using the Syntax score to predict clinical outcome in patients with three-vessel lumen obstruction undergoing percutaneous coronary intervention. Am J Cardiol 2007;99:1072-81.

9. Gensini GG. A more meaningful scoring system for determining the severity of coronary heart disease. Am J Cardiol 1983;51(3):606.

10. Ryan TJ, Faxon DP, Gunnar RM, et al. Guidelines for percutaneous transluminal coronary angioplasty. A report of the American college of cardiology/American heart association task force on assessment of diagnostic and therapeutic cardiovascular procedures (subcommittee on percutaneous transluminal coronary angioplasty). Circulation 1988;78(2):486-502.

11. Ellis SG, Vandormael MG, Cowley MJ, et al. Coronary morphologic and clinical determinants of procedural outcome with angioplasty for multi- vessel coronary disease. Implications for patient selection. Multivessel Angioplasty Prognosis Study Group. Circulation 1990;82(4):1193-202.

12. Krone RJ, Laskey WK, Johnson C, et al. A simplified lesion classification for predicting success and complications of coronary angioplasty. Registry Committee of the Society for Cardiac Angio- graphy and Intervention. Am J Cardiol 2000;85(10):1179-84.

13. Leaman DM, Brower RW, Meester GT, Serruys P, van den Brand M. Coronary artery atherosclerosis: severity of the disease, severity of angina pectoris and compromised left ventricular function. Circulation 1981;63(2):285-99.

14. Hamburger JN, Serruys PW, Scabra-Gomes R, et al. Recanalization of total coronary occlusions using a laser guidewire (the European TOTAL Surveillance Study). Am J Cardiol 1997; 80(11):1419-23.

15. Iwakura $\mathrm{K}$, Ito $\mathrm{H}$, Ikushima $\mathrm{M}$, et al. Association between hyperglycemia and the no reflow phenomenon in patients with acute myocardial infarction. J Am Coll Cardiol 2003; 41(1):1-7.

16. Lefevre T, Louvard Y, Morice MC, et al. Stenting of bifurcation lesions: classification, treatments, and results. Catheter Cardiovasc Interv 2000; 49(3):27483.

17. Ong ATL, Serruys PW, Mohr FW, et al. The SYNergy between percutaneous coronary 
intervention with TAXus and cardiac surgery (SYNTAX) study: design, rationale, and run-in phase. Am Heart J 2006; 151(6):1194-204.

18. Thel MC, Califf RM, Tardiff BE, et al. Timing of and risk factors for myocardial ischemic events after percutaneous coronary intervention (IMPACT-II). Integrilin to minimize platelet aggregation and coronary thrombosis. Am J Cardiol 2000; 85(4):427-34.

19. Van Gaal WJ, Choudhury RP, Porto I, et al. Prediction of distal embolization during percutaneous coronary intervention in saphenous vein grafts. Am J Cardiol 2007; 99(5):603-6. 